\title{
O FINANCIAMENTO DA EDUCAÇÃO E QUESTÕES CONSTITUCIONAIS CONTEMPORÂNEAS NO BRASIL
}

\section{THE FINANCING OF EDUCATION AND CONTEMPORARY CONSTITUTIONAL ISSUES IN BRAZIL}

\section{EL FINACIAMIENTO DE LA EDUCACIÓN Y CUESTIONES CONSTITUCIONALES CONTEMPORÁNEAS EN BRASIL}

Bruno Oliveira dos Santos ${ }^{1}$

Edivaldo Machado Boaventura ${ }^{2}$ Francisca de Paula Santos da Silva ${ }^{3}$

\begin{abstract}
RESUMO: O presente artigo objetiva demonstrar, através de argumentos jurídicos, a inaplicabilidade da Emenda Constitucional No 95 de 2016, a qual inseriu o Art. 107 nos Atos das Disposições Constitucionais Transitórias da Constituição Federal Brasileira de 1988, o qual limita os gastos do governo por um período de vinte exercícios financeiros, no que se refere ao financiamento da Educação, considerando os Princípios da Unidade da Constituição, da Cidadania e da Dignidade da Pessoa Humana. Outrossim, objetiva também, demonstrar que existem mecanismos judicias específicos que podem ser utilizados pela sociedade civil. A metodologia utilizada foi a hermenêutica constitucional com base na ponderação de princípios constitucionais. Posto isso, conclui-se pela inconstitucionalidade da emenda, devendo esta ser expurgada do ordenamento jurídico, não se aplicando, por via oblíqua, quanto ao financiamento da educação.
\end{abstract}

Palavras-chave: Limitação de gastos públicos. Inconstitucionalidade. Financiamento da Educação. Unidade da Constituição. Inaplicabilidade.

Submetido em: 21/05/2018 - Aceito em: 21/06/2018 - Publicado em: 26/06/2018.

${ }^{1}$ Doutorando em Difusão do Conhecimento pela Universidade Federal da Bahia - UFBA, Brasil;

Mestre em Desenvolvimento Regional e Urbano pela Universidade Salvador, Laureate International Universities - UNIFACS, Brasil; Especialista lato sensu em Direito Público pelo Instituto de Educação Luiz Flávio Gomes IELF, Brasil; Docente na Graduação da Universidade Paulista - UNIP, Brasil; Membro do Instituto Geográfico e Histórico da Bahia - IGHB, Brasil; Advogado, Consultor Jurídico e Parecerista; E-mail: brunoadv.72@gmail.com 2 Doutor em Direito pela Universidade Federal da Bahia - UFBA, Brasil; PhD e Mestre em Administração Educacional pela The Pennsylvania State University - PENN STATE, USA; Bacharel em Direito e Ciências Sociais pela Universidade Federal da Bahia - UFBA, Brasil; Professor Emérito e Livre Docente da Universidade Federal da Bahia - UFBA, Brasil; Professor Titular da Universidade Salvador, Laureate International Universities - UNIFACS, Brasil; E-mail: edivaldoboaventura@gmail.com

3 Pós-Doutora em Educação pela Universidade de Coimbra - UC, Portugal; Doutora em Educação pela Universidade Federal da Bahia - UFBA, Brasil; Mestre em Administração pela Universidade Federal da Bahia UFBA, Brasil; Bolsista de Produtividade Desen. Tec. e Extensão Inovadora do CNPQ - Nível 2;

Professora Titular Plena da Universidade do Estado da Bahia - UNEB, Brasil; E-mail: fcapaula@ gmail.com 
ABSTRACT: The purpose of this article is to demonstrate, through legal arguments, the inapplicability of Constitutional Amendment $\mathrm{N}^{\circ} 95$ of 2016, which inserted Art. 107 in the Acts of Transitional Constitutional Provisions of the Brazilian Federal Constitution of 1988, which limits the Government for a period of twenty financial years, regarding the financing of Education, considering the Principles of Unity of the Constitution, Citizenship and Dignity of the Human Person. It also aims to demonstrate that there are specific judicial mechanisms that can be used by civil society. The methodology used was constitutional hermeneutics based on the weighting of constitutional principles. Having said this, it is concluded that the amendment is unconstitutional, and that it must be expunged from the legal system, not being applied, to the financing of education.

Keywords: Limitation of public spending. Unconstitutionality. Financing of Education. Unit of the Constitution. Inapplicability.

RESUMÉN: El presente artículo busca, a través de argumentos jurídicos, la inaplicabilidad de la Enmienda Constitucional $n^{\circ} 95$ de 2016, la cual incorpora el Artículo 107 en los Actos de las Disposiciones constitucionales Transitorias de la Constitución Federal Brasileña de 1988, el cual limita los gastos del gobierno por un período de veinte ejercicios financieros, en lo que se refiere al financiamiento de la educación, considerando los Principios de la Unidad de la Constitución, de la Ciudadanía y de la Dignidad de la Persona Humana. De otra manera, también tiene por objetivo, demostrar que existen mecanismos judiciales específicos que pueden ser utilizados por la sociedad civil. La metodología utilizada fue la hermenéutica constitucional con base en la ponderación de principios constitucionales. Se concluye por la inconstitucionalidad de la enmienda, debiendo ser expurgada de la orden jurídica, ya que no se aplica, por vía obligatoria, al financiamiento de la educación.

Palabras clave: Limitación de gastos públicos. Inconstitucionalidad. Financiamiento de la Educación. Unidad de la Constitución.

\section{INTRODUÇÃO}

É notório e sabido, que o Brasil nos últimos anos está passando por uma grave crise econômica decorrente de inúmeros fatores a saber: implementação de políticas econômicas equivocadas nos últimos anos; a redução do preço das commodites exportadas pelo país no mercado internacional; queda na arrecadação; aumento desenfreado dos gastos públicos; governos coniventes com práticas ilícitas; dentre outros fatores.

Nesse contexto, foi aprovado pelo Congresso Nacional o Projeto de Emenda Constitucional $N^{\circ} 241$ (PEC 241), o qual foi convertido na Emenda Constitucional tombada 


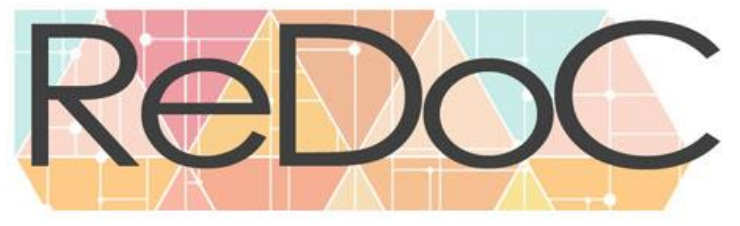

Revista Docência e Cibercultura

sob o $\mathrm{N}^{\circ} 95$ de 2016, a qual limita os gastos públicos por um prazo de vinte exercícios financeiros (vinte anos), contados a partir do ano de 2018.

Todavia, não devemos esquecer que a Constituição Federal Brasileira de 1988 consagra princípios que garantem o mínimo de dignidade a todo e qualquer cidadão, dentre eles o direito à Educação.

Nesse contexto, estariam os financiamentos da Educação atingidos por este novo mandamento constitucional?

A resposta para tal questionamento será encontrada a partir das reflexões acerca do Princípio Constitucional da Unidade da Constituição, da Dignidade da Pessoa Humana e da Cidadania.

\section{ACEPÇÃO DE EDUCAÇÃO EM SEU SENTIDO AMPLO: TRATAMENTO DO TEMA NA CONSTITUIÇÃO FEDERAL BRASILEIRA DE 1988}

A Educação, em sentido amplo, representa tudo aquilo que pode ser feito para desenvolver o ser humano e, no sentido estrito, representa a instrução e o desenvolvimento de competências e habilidades.

Desde a Grécia antiga que se teorizava sobre a Educação. Para Aristóteles, a educação deve levar o homem a alcançar a sua plena realização, mas isso só se torna possível se ele desenvolver suas faculdades físicas, morais e intelectuais.

Partindo dessa premissa básica, muitos confundem os conceitos de "ensino", “aprendizagem" e "educação". O ensino é uma prática eminentemente ligada à instrução, ou seja, é uma forma sistemática de transmissão de conhecimentos utilizada pelos humanos para instruir os seus semelhantes, geralmente em locais conhecidos como escolas.

O ensino pode ser praticado de diferentes formas. As principais são: o ensino formal e o ensino informal. O ensino formal é aquele praticado pelas instituições de ensino, com respaldo de conteúdo, forma, certificação, profissionais de ensino, dentre outros. O ensino informal está relacionado ao processo de socialização do homem, ocorrendo durante toda a vida, muitas vezes de forma não intencional. 
Para Neuner (1981, p. 254), "a linha fundamental do processo de ensino é a transmissão e apropriação de um sólido sistema de conhecimentos e capacidades duradouras e aplicáveis." Destaca-se por um lado neste conceito, a menção de "um sólido sistema de conhecimento" e, por outro, as "capacidades duradouras e aplicáveis". Assim, o primeiro, refere-se ao processo de instrução, o qual procura atingir a superação dos discentes, e o segundo, ao treinamento como forma de desenvolvimento de suas capacidades.

Em outras palavras, o ensino é uma prática instrucional com vistas à apropriação do educando de habilidades e competências específicas para necessidades específicas, as quais são exigidas pelo contexto social em que o indivíduo está inserido, a exemplo das habilidades e competências exigíveis para o mercado de trabalho.

No que se refere ao processo de aprendizagem, este, diferentemente do ensino, possui um aspecto mais abrangente, tendo em vista que corresponde ao desenvolvimento cognitivo de processos contínuos de apreensão de habilidades e competências, o que para Skinner (1972), "é o ajustamento ou adaptação a uma situação", enquanto para Vygotsky (1998), equivale "ao processo pelo qual o sujeito adquire informações, habilidades, atitudes e valores, a partir do seu contato com a realidade, com o meio ambiente e outras pessoas".

No que se refere a "Educação", esta deve ser compreendida numa acepção transdisciplinar para além do ensino e da aprendizagem, orientada na perspectiva da formação plena do indivíduo, em seus aspectos sociológicos, éticos, políticos e da cidadania (FREIRE, 1982).

Assim, não é por acaso, que a “educação" está consagrada na Constituição Federal Brasileira de 1988 como um direito fundamental de natureza social, conforme verificado em seu Art. $6^{\circ}$. Assim, leia-se:

Art. $6^{\circ}$ São direitos sociais a educação, a saúde, a alimentação, o trabalho, a moradia, o transporte, o lazer, a segurança, a previdência social, a proteção à maternidade e à infância, a assistência aos desamparados, na forma desta Constituição (grifo nosso).

Segundo Dirley da Cunha Júnior (2009, p. 130), direitos fundamentais são aquelas normas de cunho constitucional que disciplinam e vinculam toda a atuação estatal, as quais 
impõem ao poder público o poder de proteger a vida humana no seu nível de dignidade, de modo a realizar, em última instância, a felicidade humana.

Em relação aos direitos de natureza social, José Afonso da Silva (1992, p. 258) compreende como prestações positivas estatais enunciadas em normas constitucionais, as quais possibilitam melhores condições de vida aos mais fracos, direitos estes que tendem a realizar a igualização de situações sociais desiguais.

Postas estas premissas, a Constituição Federal Brasileira de 1988 confere um status significativo ao Direito à Educação, de modo a discipliná-lo locus específico, qual seja, o Capítulo III, Seção I, Art. 205, o qual consagra o Direito à Educação numa concepção transdisciplinar, democratizando-o a todos indistintamente, obrigando o Estado e a sociedade civil a promovê-lo e incentivá-lo. Assim, leia-se:

\section{Capítulo III}

Da Educação, da Cultura e do Desporto

Seção I

Da Educação

Art. 205. A educação, direito de todos e dever do Estado e da família, será promovida e incentivada com a colaboração da sociedade, visando ao pleno desenvolvimento da pessoa, seu preparo para o exercício da cidadania e sua qualificação para o trabalho.

Nessa diretriz, considerando a maneira como é tratado o Direito à Educação pela Lei Maior do Estado numa acepção ampla, para efetivá-lo, não basta apenas consagrá-lo no documento constitucional. Assim, além dos aspectos legais, deverá o Estado garanti-lo mediante políticas públicas, considerando que o Direito à Educação é um direito subjetivo que, no pensamento de Boaventura (1997), significa dizer que, para ser considerado um direito de todos, deverá ser garantida escolas para todos e, não existindo, deterá o indivíduo a faculdade de exigir dos poderes públicos o cumprimento da prestação educacional, podendo os gestores públicos incorrerem em crime de responsabilidade, à luz do quanto disposto no Art. 208, $\S \S 1^{\circ}$ e $2^{\circ}$ da Constituição Federal de 1988:

Art. 208. O dever do Estado com a educação será efetivado mediante a garantia de:

\section{(...)}

$\S 1^{\circ} \mathrm{O}$ acesso ao ensino obrigatório e gratuito é direito público subjetivo. 
$\S 2^{\circ} \mathrm{O}$ não-oferecimento do ensino obrigatório pelo Poder Público, ou sua oferta irregular, importa responsabilidade da autoridade competente (grifos nossos).

Interpretando o dispositivo supracitado, Manoel Gonçalves Ferreira Filho (apud BOAVENTURA, 2010) entende o seguinte:

O direito ao ensino obrigatório ( $1^{\circ}$ grau) e gratuito é reconhecido como direito público subjetivo. Disto resulta que o titular desse direito poderá fazê-lo valer em juízo contra o Estado, que deverá assegurar-lhe matrícula em escola pública ou bolsa de estudos em escola particular (Art. 213, § $1^{\circ}$ ), no caso de ausência de vagas nos cursos públicos.

Pontes de Miranda (1963, p. 218) é bastante enfático ao pontuar que um direito consagrado na Constituição sem a existência de uma política pública para a sua efetivação é simplesmente uma letra inócua, ilusória e retórica, ficando simplesmente adstrita ao plano das intenções. Assim, leia-se:

A ingenuidade ou a indiferença ao conteúdo dos enunciados com que os legisladores constituintes lançam a regra "A educação é direito de todos", lembra-nos aquela Constituição espanhola em que se decretava que todos 'os espanhóis seriam', desde aquele momento, 'buenos'. A educação somente pode ser direito de todos se houver escolas em número suficiente e se ninguém é excluído delas, portanto se há direito público subjetivo à educação, o Estado tem o dever de entregar a prestação educacional. Fora daí, é iludir com artigos de Constituição ou de leis. Resolver o problema da educação não é fazer leis, ainda que excelentes; é abrir escolas, tendo professores e admitindo os alunos.

Ainda em relação ao Art. 208 da Constituição Federal ora citado, este estabelece as diretrizes que o Estado deve observar para garantir o direito à Educação em seu aspecto amplo:

Art. 208. O dever do Estado com a educação será efetivado mediante a garantia de:

I - educação básica obrigatória e gratuita dos 4 (quatro) aos 17 (dezessete) anos de idade, assegurada inclusive sua oferta gratuita para todos os que a ela não tiveram acesso na idade própria;

II - progressiva universalização do ensino médio gratuito;

III - atendimento educacional especializado aos portadores de deficiência, preferencialmente na rede regular de ensino;

IV - educação infantil, em creche e pré-escola, às crianças até 5 (cinco) anos de idade;

\begin{tabular}{|l|l|l|l|l|l|l|}
\hline (C) Redoc & Rio de Janeiro & v.2 & n.2 & p. 18 & Maio/Agosto. 2018 & ISSN 2594-9004 \\
\hline
\end{tabular}


V - acesso aos níveis mais elevados do ensino, da pesquisa e da criação artística, segundo a capacidade de cada um;

VI - oferta de ensino noturno regular, adequado às condições do educando;

VII - atendimento ao educando, em todas as etapas da educação básica, por meio de programas suplementares de material didáticoescolar, transporte, alimentação e assistência à saúde.

Nessa diretriz, conforme verificado, o rol de políticas que a Constituição obriga o poder público a executar para a efetivação do direito à Educação é significativo, necessitando para tanto, de um montante significativo de recursos

Nesse sentido, eventual limite de gastos em relação ao financiamento da Educação deverá considerar outras variáveis previstas na Constituição Federal, o que será constatado nos capítulos a seguir.

INAPLICABILIDADE DA EMENDA CONSTITUCIONAL N N $^{\circ}$ DE 2016 EM RELAÇÃO AO FINANCIAMENTO DA EDUCAÇÃO: PONDERAÇÃO DE PRINCÍPIOS ENTRE A UNIDADE DA CONSTITUIÇÃO, DIGNIDADE HUMANA E CIDADANIA

Antes de adentrarmos às reflexões sobre as ideias do presente capítulo, é importante salientar que o Brasil possui um estoque significativo de desigualdades produzido ao longo de séculos. Posto isso, toda e qualquer medida econômica não deve desconsiderar tal realidade. Nessa diretriz, medidas que ensejem cortes de políticas sociais devem ser avaliadas e implementadas com ponderações.

Considerando a crise econômica instaurada no país, o governo atual encaminhou o Projeto de Emenda Constitucional № 241, também conhecido como "PEC dos gastos", o qual foi aprovado pelas duas casas do Congresso Nacional, sendo posteriormente promulgado e convertido na Emenda Constitucional $\mathrm{N}^{\circ} 95$ de 2016. Assim, foi incluído no Ato das Disposições Constitucionais Transitórias (ADCT) o Art. 106 com a seguinte redação:

Art. 106. Fica instituído o Novo Regime Fiscal no âmbito dos Orçamentos Fiscal e da Seguridade Social da União, que vigorará por vinte exercícios 
financeiros, nos termos dos arts. 107 a 114 deste Ato das Disposições Constitucionais Transitórias.

Por sua vez, o Art. 107 do ADCT tem a seguinte redação:

Art. 107. Ficam estabelecidos, para cada exercício, limites individualizados para as despesas primárias:

I - do Poder Executivo;

II - do Supremo Tribunal Federal, do Superior Tribunal de Justiça, do Conselho Nacional de Justiça, da Justiça do Trabalho, da Justiça Federal, da Justiça Militar da União, da Justiça Eleitoral e da Justiça do Distrito Federal e Territórios, no âmbito do Poder Judiciário;

III - do Senado Federal, da Câmara dos Deputados e do Tribunal de Contas da União, no âmbito do Poder Legislativo;

IV - do Ministério Público da União e do Conselho Nacional do Ministério Público; e

V - da Defensoria Pública da União.

$\S 1^{\circ}$ Cada um dos limites a que se refere o caput deste artigo equivalerá:

I - para o exercício de 2017, à despesa primária paga no exercício de 2016, incluídos os restos a pagar pagos e demais operações que afetam o resultado primário, corrigida em 7,2\% (sete inteiros e dois décimos por cento); e

II - para os exercícios posteriores, ao valor do limite referente ao exercício imediatamente anterior, corrigido pela variação do Índice Nacional de Preços ao Consumidor Amplo - IPCA, publicado pelo Instituto Brasileiro de Geografia e Estatística, ou de outro índice que vier a substituí-lo, para o período de doze meses encerrado em junho do exercício anterior a que se refere a lei orçamentária.

$\S 2^{\circ}$ Os limites estabelecidos na forma do inciso IV do caput do art. 51, do inciso XIII do caput do art. 52 , do $\S 1^{\circ}$ do art. 99 , do $\S 3^{\circ}$ do art. 127 e do $\S 3^{\circ}$ do art. 134 da Constituição Federal não poderão ser superiores aos estabelecidos nos termos deste artigo.

Assim, conforme verificado no Art. $107, \S 1^{\circ}$, I e II, a partir do exercício financeiro de 2018, o limite de aumento de gastos para os exercícios seguintes será pelo percentual do índice de inflação do exercício anterior. Ocorre que, tal limite é mitigado pela própria Constituição Federal, no que se refere ao financiamento da Educação, considerado o Princípio da Unidade da Constituição. 


\section{O PRINCÍPIO DA UNIDADE DA CONSTITUIÇÃO E OS PERCENTUAIS PREVISTOS PARA O FINANCIAMENTO DA EDUCAÇÃO}

Antes de se conhecer os parâmetros de financiamento da Educação, é preciso, primeiramente, o conhecimento da técnica de hermenêutica do Princípio da Unidade da Constituição.

A Constituição Federal, por se tratar da norma maior do Estado, não é um simples ideário, ou seja, não é apenas uma expressão de anseios, de aspirações, de propósitos. Pelo contrário, é a transformação de um ideário, é a conversão de anseios e aspirações em regras impositivas, tanto para todas as estruturas de poder do Estado, quanto para os particulares. Assim, as normas jurídicas constitucionais não são conselhos, opinativos ou sugestões, mas determinações (MELLO, 2009).

Para tanto, a Constituição consagra determinados princípios que devem ser observados. Karl Larenz (apud ÁVILA, 2011, p. 97), define os princípios como normas de grande relevância para o ordenamento jurídico, na medida que estabelecem fundamentos normativos para a interpretação e aplicação do Direito, deles decorrendo, direta ou indiretamente, normas de comportamento.

Por se tratar de normas fundantes do ordenamento jurídico, a violação de um princípio é mais grave que violar uma regra, por se tratar de insurgência de um sistema pré-estabelecido de valores fundamentais de um ordenamento jurídico. Assim, vejamos o entendimento de Celso Antônio Bandeira de Mello (2005, p. 902) a respeito:

\footnotetext{
Violar um princípio é muito mais grave que transgredir uma norma qualquer. A desatenção ao princípio implica ofensa não apenas a um mandamento obrigatório, mas a todo o sistema de comandos. É a mais grave ilegalidade ou inconstitucionalidade, conforme o escalão do princípio atingido, porque representa insurgência contra todo o sistema, subversão de seus valores fundamentais, contumélia irremissível a seu arcabouço lógico e corrosão de sua estrutura mestra.
}

Nessa diretriz, Ávila (2011, p. 97) endossa que os princípios são dotados de eficácia direta, pois atuam sobre outras normas sem intermediação ou interposição de uma regra, ou seja, no plano da eficácia direta, os princípios exercem uma função integrativa, à medida que 


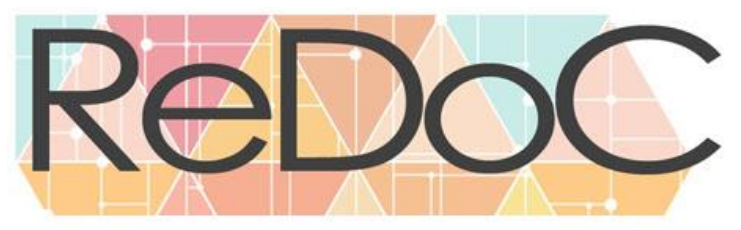

Revista Docência e Cibercultura

justificam agregar elementos não previstos em subprincípios ou regras. Dentre as técnicas de interpretação dos princípios constitucionais, destaca-se o Princípio da Unidade da Constituição.

Segundo Dirley da Cunha Júnior (2010, p. 216), o Princípio da Unidade da Constituição, da Concordância Prática ou Harmonização, serve ao propósito de impor ao intérprete a coordenação e harmonização dos bens jurídicos constitucionais em conflito, de modo a evitar o sacrifício de uns em relação aos outros.

Este princípio decorre da unidade da Constituição, sendo utilizado para resolver colisões entre direitos fundamentais ou entre direitos fundamentais e outros bens jurídicos constitucionalmente protegidos. A premissa que fundamenta este princípio, é a ideia de que todos os bens jurídico-constitucionais ostentam igual valor, situação que impede a negação de um em face de outro ou vice-versa, além de impor limites e condicionamentos recíprocos, de modo a alcançar uma harmonização ou concordância prática entre eles.

Assim, a priori, a nova regra de limite dos gastos públicos, já encontra óbices no Art. 212 da Constituição Federal, que vincula o percentual de gastos que a União, os Estados, o Distrito Federal e os Municípios devem observar em relação às ações de manutenção e desenvolvimento do ensino, o qual prescreve que a União deve gastar nunca menos que $18 \%$ da receita resultante de impostos, compreendida inclusive aquela proveniente de transferências, sendo o percentual de 25\% para Estados, Distritos Federal e Municípios:

Art. 212. A União aplicará, anualmente, nunca menos de dezoito, e os Estados, o Distrito Federal e os Municípios vinte e cinco por cento, no mínimo, da receita resultante de impostos, compreendida a proveniente de transferências, na manutenção e desenvolvimento do ensino.

Nesse sentido, numa interpretação a priori, os percentuais previstos no dispositivo supracitado não podem ser minorados, mas atualizados no exercício seguinte pelo percentual do índice da inflação do exercício anterior. Todavia, o entendimento proposto no presente trabalho inclina-se no sentido oposto, considerando que existem outros princípios que impedem esse limite de atualização, quais sejam, o Princípios da Dignidade da Pessoa Humana e da Cidadania, os quais trataremos com maiores detalhes no item a seguir. 


\section{DIGNIDADE DA PESSOA HUMANA E CIDADANIA VERSUS ART. 107 DO}

\section{ADCT}

Preliminarmente, é preciso que seja alertado que se essa regra do limite de gastos públicos previstos no Art. 107 do ADCT for rigorosamente seguida, poderá potencializar a precarização da Educação, pois o estabelecimento de um limite de aumento de gastos com Educação pelo índice da inflação do exercício anterior, limitaria a contratação de professores, o financiamento dos programas suplementares de transporte escolar, material didático e merenda escolar, os investimentos em infraestrutura das unidades educacionais, dentre outros desdobramentos.

Segundo o pensamento de Amartya Sen (2010), a Educação é um dos vetores primordiais para o desenvolvimento e progresso de um povo, tendo em vista que o próprio desenvolvimento consiste na remoção dos vários tipos de restrições que limitam as escolhas e a democratização de oportunidades para as pessoas que procuram essencialmente viver bem e por muito tempo.

Para tanto, as realizações ao alcance de cada um dependem das oportunidades econômicas, das liberdades políticas, dos poderes sociais, da boa saúde, da educação básica e dos incentivos e estímulos às suas iniciativas.

Endossando o pensamento de Amartya Sen, partimos da premissa de Kant (apud MENDES, 2009) que o ser humano não pode ser considerado um mero instrumento do Estado para atingir os seus objetivos, mas o contrário, o ser humano é a finalidade maior do Estado, o que corresponde à própria concepção de dignidade humana. Portanto, nenhuma política econômica do Estado, deve desconsiderar a situação de miserabilidade de seu povo, que é o caso da realidade brasileira.

Nessa diretriz, a Dignidade da Pessoa Humana antecede até mesmo ao próprio Direito, pois esta é a condição necessária para a sua aplicação, e é justamente essa lógica do plano das finalidades, que se impõe a necessidade do Estado agir nesse sentido, o que na lição de José Afonso da Silva (2001), é um valor supremo que atrai o conteúdo de todos os direitos fundamentais do homem. Logo, o princípio tem por finalidade estatuir que todos os homens 
estão numa mesma situação jurídica, o que decorre do fato de pertencer a uma mesma natureza, que é dita humana, conforme o pensamento de Adorno (1998, p. 61).

Con tal principio se quiere destacar que ya no se admite actualmente la existência de hombres de segunda categoria, de sub-humanos, de vidas sin valor vital. Es suficiente con ser hombre para ser reconecido como persona. Todos los hombres son igualmente dignos, em razon de su naturaleza común. Ser digno equivale, por tanto, a ser persona.

Portanto, este critério vincula inclusive os legisladores, de modo a convertê-los em súditos desta regra, à medida que toda e qualquer regra criada por esses sofre limitações, quando prejudicam políticas públicas de efetivação do progresso da dignidade humana.

A Cidadania, por sua vez, está umbilicalmente ligada à Dignidade da Pessoa Humana, o que em linhas gerais, segundo entendimento majoritário, pressupõe a observância dos direitos relativos à liberdade, à participação política e os direitos sociais.

No pensamento de Milton Santos (1995, p. 18), o simples nascer investe o indivíduo de uma soma inalienável de direitos, apenas pelo fato de ingressar na sociedade humana. Para o referido pensador, viver, tornar-se um ser no mundo, é assumir com os demais uma herança moral, que faz com que cada qual seja um portador de prerrogativas sociais, isto é, de ter direito ao teto, à comida, à educação, à saúde, ao trabalho, à justiça, à liberdade e a uma existência digna.

Postas estas premissas, reforça Santos, que para que a cidadania não esteja circunscrita apenas ao plano do discurso, é preciso que esta tenha força normativa que confira obrigatoriedade de obediência.

Assim, para que a cidadania seja mantida pelas gerações sucessivas, para ter eficácia e ser fonte de direitos, ela deve estar inscrita nas leis, mediante dispositivos institucionais que assegurem a fruição das prerrogativas compactuadas entre a Sociedade Civil e o Estado, de modo que a violação de tais prerrogativas, deverá ensejar o direito de serem reclamadas e exigíveis de cumprimento pelas instâncias públicas.

Nessa diretriz, o cidadão é uma categoria política, a qual só tem eficácia enquanto categoria jurídica, tendo em vista que o arcabouço jurídico e constitucional, constitui uma garantia em prol do indivíduo, o que lhe garante proteção contra violações de suas prerrogativas. 
Não é por acaso, que tanto a Dignidade Humana como a Cidadania, estão expressamente positivadas na Constituição Federal brasileira, na qualidade de fundamento da República Federativa do Brasil. Assim, vejamos o quanto disposto no Art. $1^{\circ}$, II e III:

Art. $1^{\circ}$ A República Federativa do Brasil, formada pela união indissolúvel dos Estados e Municípios e do Distrito Federal, constitui-se em Estado Democrático de Direito e tem como fundamentos:

I - a soberania;

II - a cidadania

III - a dignidade da pessoa humana;

IV - os valores sociais do trabalho e da livre iniciativa;

V - o pluralismo político.

Parágrafo único. Todo o poder emana do povo, que o exerce por meio de representantes eleitos ou diretamente, nos termos desta Constituição.

Os fundamentos da República são os princípios fundamentais que explicitam as valorações políticas fundamentais do legislador constituinte, as quais explicitam as valorações políticas fundamentais, que devem servir de orientação à conduta dos agentes políticos do Estado (CANOTILHO, 1980).

É importante salientar que os fundamentos da República Federativa do Brasil são considerados cláusulas pétreas, ou seja, dispositivos insuscetíveis de supressão ou mitigação pelo legislador constituinte reformador.

Feitas estas considerações, considerando o Princípio da Unidade da Constituição e os princípios da Dignidade da Pessoa Humana e da Cidadania, entendemos que o limite estabelecido pelo Art. 107 do ADCT em relação aos gastos com Educação, não poderão ser aplicados em hipótese alguma, tendo em vista a precarização que pode ensejar em seus diversos níveis, seja na educação básica ou na educação superior.

Sendo assim, limitar os gastos com Educação, significa limitar as oportunidades de mobilidade social de uma parcela significativa da população brasileira, prejudicando inclusive o futuro do país, no que se refere a investimentos em inovação e ciência, retrocedendo o Brasil no quesito competitividade em relação aos demais países do mundo. 


\section{INSTRUMENTOS JURÍDICOS DE DEFESA DA SOCIEDADE CONTRA A LIMITAÇÃO DOS GASTOS COM EDUCAÇÃO.}

Ante o exposto, considerando os argumentos expostos no presente artigo, o cidadão e os diversos segmentos da sociedade civil, notadamente os representativos do segmento da Educação, podem se utilizar de instrumentos jurídicos específicos para obstar as tentativas de limitações dos gastos com educação promovidas pelos gestores públicos.

Dentre eles, destacamos a Ação Civil Pública, consubstanciada na Lei N 7.347, de 24 de julho de 1985, a Ação Popular, consubstanciada na Lei $\mathrm{N}^{\circ}$ 4.717, de 29 de junho de 1965, além do Mandado de Segurança, consubstanciado na Lei $\mathrm{N}^{\circ} 12.016$, de 7 de agosto de 2009.

Outro instrumento jurídico que poderá ser manejado, é a Ação Direta de Inconstitucionalidade, prevista no Art. 103 da Constituição Federal de 1988 e regulamentada pela Lei $\mathrm{N}^{\circ} 9.868$, de 10 de novembro de 1999, de modo a expurgar do ordenamento jurídico brasileiro a Emenda Constitucional $\mathrm{N}^{\circ} 95$ de 2016, a qual incluiu o dispositivo que impõe o limite de gastos no Art. 107 do ADCT, considerando que o próprio Supremo Tribunal Federal (STF), órgão máximo do Poder Judiciário e responsável pela guarda da Constituição, já sedimentou precedentes no sentido de que uma emenda constitucional estará sujeita a controle de constitucionalidade, quando esta violar cláusula pétrea, o que no caso em tela, viola princípios atinentes aos fundamentos da República, quais sejam, Cidadania e Dignidade da Pessoa Humana. Assim, leia-se a transcrição literal de um precedente da Suprema Corte nesse sentido:

A eficácia das regras jurídicas produzidas pelo poder constituinte (redundantemente chamado de "originário") não está sujeita a nenhuma limitação normativa, seja de ordem material, seja formal, porque provém do exercício de um poder de fato ou suprapositivo. Já as normas produzidas pelo poder reformador, essas têm sua validez e eficácia condicionadas à legitimação que recebam da ordem constitucional. Daí a necessária obediência das emendas constitucionais às chamadas cláusulas pétreas.

[ADI 2.356 MC e ADI 2.362 MC, rel. p/ o ac. min. Ayres Britto, j. 25-112010, P, DJE de 19-5-2011].

Posto isso, é importante salientar, que a causa de pedir da Ação Civil Pública, da Ação Popular e do Mandado de Segurança é o ato administrativo do gestor que limita os gastos com 
a Educação com base na emenda constitucional $n^{\circ} 95$ de 2016, atacável consoante os fundamentos jurídicos esboçados no presente artigo. Logo, as referidas ações judiciais podem ser utilizadas em sede de controle difuso de constitucionalidade, enquanto que a Ação Direta de Inconstitucionalidade é utilizada em sede de controle concentrado de constitucionalidade, cujo o objeto é a própria emenda, considerando o entendimento do STF supracitado.

Registre-se, que já está em trâmite no STF, uma Ação Direta de Inconstitucionalidade intentada pela Partido Socialismo e Liberdade (PSOL), a qual questiona a referida emenda constitucional, sendo que num dos trechos da petição inicial4, é ressaltada a importância que o Poder Constituinte Originário conferiu ao financiamento da Educação no Brasil:

Com efeito, o dispositivo constitucional do art. 212, que estabelece a obrigatoriedade da União em aplicar um mínimo de $18 \%$ da receita proveniente de impostos na educação, foi incorporado ao texto constitucional de 1988 por unanimidade na comissão de sistematização da Assembleia Nacional Constituinte.

Algo que demonstra o forte consenso formado ao longo de anos de desenvolvimento institucional brasileiro acerca da importância dos investimentos em educação para o desenvolvimento. Diferentemente de outros países, que universalizaram a educação básica e implementaram programas audaciosos de educação média e superior ainda no século XIX, o Brasil até hoje ainda sofre com o drama do analfabetismo, da baixa escolaridade e da exclusão de amplas parcelas da população do acesso à educação pública. Uma chaga que o constituinte decidiu enfrentar de modo

\section{CONCLUSÕES} consistente por meio de tal dispositivo.

Ante o exposto, concluímos que à luz dos Princípios da Unidade da Constituição, da Cidadania e da Dignidade da Pessoa Humana, que o limite de gastos introduzidos pela Emenda Constitucional $N^{\circ} 95$ de 2016 não se aplica ao financiamento da Educação, face à sua inconstitucionalidade, podendo ser manejado pela sociedade civil os instrumentos jurídicos da Ação Direta de Inconstitucionalidade, em sede de controle concentrado de constitucionalidade, além de outras ações constitucionais, tais como Ação Popular, Ação Civil Pública e Mandado de Segurança, em sede de controle difuso de constitucionalidade.

\footnotetext{
${ }^{4}$ NASSIF, Luis. PSOL Entra com Ação no STF Contra Emenda do Teto de Gastos. Site Jornal GGN. Seção Página Inicial. Disponível em: <http://jornalggn.com.br/sites/default/files/documentos/adicontra-ec-95-teto-de-gastos.pdf $>$. Acesso em: 17 abr. 2017.
} 
A propósito, fomentar o manejo de tais instrumentos jurídicos, suscitaria o debate sobre o tema em diversos espaços institucionais, não se limitando apenas ao âmbito do poder judiciário.

Assim, legitimar o dispositivo constitucional previsto no Art. 107 do ADCT no que se refere as ações de manutenção e desenvolvimento do ensino, potencializará a precarização da Educação no Brasil em seus diversos níveis, seja em relação à educação básica, seja em relação ao ensino superior.

Outrossim, tal medida, inevitavelmente, limitará as oportunidades de mobilidade social de uma parcela significativa da população brasileira, prejudicando o desenvolvimento do país, sobretudo no que se refere aos investimentos em inovação, ciência e tecnologia, retrocedendo o Brasil no quesito competitividade em relação aos demais países do mundo, consolidando a sua posição de periferia do capitalismo global.

\section{REFERÊNCIAS}

ADORNO, Roberto. Bioética y Dignidad de la Persona. Madrid: Tecnos, 1998.

ÁVILA, Humberto. Teoria dos Princípios. 12 ed. São Paulo: Malheiros, 2011.

ALEXY, Robert. Teoria dos Direitos Fundamentais. Tradução de Virgílio Afonso da Silva. 2. ed. São Paulo: Malheiros, 2011.

BOAVEnTURA, Edivaldo M. A Educação Brasileira e o Direito. 2. ed. Belo Horizonte: Nova Alvorada, 1997.

BRANCO, Maurício de Melo Teixeira; BARROS, Renato da Costa Lino de Góes; PAMPLONA FILHO, Rodolfo Mário Veiga. Revista da Academia de Letras Jurídicas da Bahia, Salvador, ano. 18, n. 20, p. 167-197, dez, 2016.

BRASIL. Constituição (1988). Constituição da República Federativa do Brasil. Brasília, DF: Senado Federal, 1988.

CANOTILHO, J. J. Gomes. Direito Constitucional e Teoria da Constituição. 5. ed. Coimbra: Coimbra Ed., 1980. 


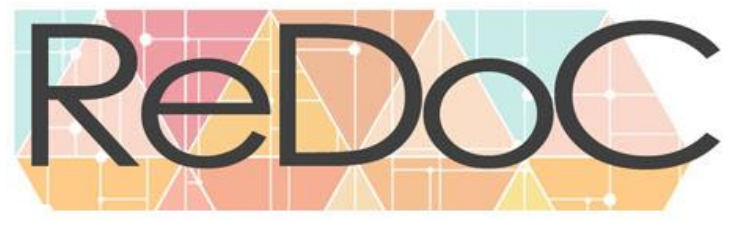

Revista Docência e Cibercultura

CUNHA JÚNIOR, Dirley Da. Controle Judicial das Omissões do Poder Público. 2. ed. São

Paulo: Saraiva, 2004.

CUNHA JÚNIOR, Dirley Da. Curso de Direito Constitucional. 2. ed. Salvador: Juspodivm, 2008.

FREIRE, Paulo. Pedagogia do Oprimido. 17. ed. Rio de Janeiro: Paz e Terra, 1987.

LUAIZA, Benito Almaguer. Educação, Ensino e Instrução. Disponível em: $<$ http://br.monografias.com/trabalhos3/educacao-ensino-instrucao/educacao-ensinoinstrucao2.shtml>. Acesso em: 22 fev. 2017.

MELLO. Celso Antônio Bandeira de. O Conteúdo Jurídico do Princípio da Igualdade. 3. ed. São Paulo: Malheiros, 2010.

MELLO. Celso Antônio Bandeira de. Curso de Direito Administrativo. 20. ed. São Paulo: Malheiros, 2005.

MELLO. Celso Antônio Bandeira de. Eficácia das Normas Constitucionais e Direitos Sociais. 4. ed. São Paulo: Malheiros, 2009.

MENDES, Gilmar Ferreira; COELHO, Inocêncio Martires; BRANCO, Paulo Gustavo Gonet. Curso de Direito Constitucional. 3. ed. São Paulo: Saraiva, 2008.

NASSIF, Luis. PSOL Entra com Ação no STF Contra Emenda do Teto de Gastos. Site Jornal GGN. Seção Página Inicial. Disponível <http://jornalggn.com.br/sites/default/files/documentos/adi-contra-ec-95-teto-de-gastos.pdfl.

Acesso em: 17 abr. 2017.

NEUNER, G. et al. Pedagogía. La Habana: Libros para La Educación, 1981.

OGASAWARA, Jenifer Satie Vaz. O Conceito de Aprendizagem de Skinner e Vygotsky: Um Diálogo Possível. 2009. 46 f. Monografia (graduação). Pedagogia. Universidade do Estado da Bahia - UNEB, Salvador, 2009.

PONTES DE MIRANDA. Comentários à Constituição de 1946. 3. ed. Rio de Janeiro: Borsoi, 1963.

SANTOS, Milton. Pensando o Espaço do Homem. 5. ed. São Paulo: Edusp, 2009.

SANTOS, Milton. Técnica, Espaço, Tempo: Globalização e Meio Técnico-Científico Informacional. 4. ed. São Paulo: Edusp, 2008.

SANTOS, Milton. Espaço do Cidadão. 4. ed. Petrópolis: Vozes, 2008. 


\section{Revista Docência e Cibercultura}

SEN, Amartya. Desenvolvimento como Liberdade. 3. ed. Rio de Janeiro: Cia das Letras, 2016.

SILVA, José Afonso da. Curso de Direito Constitucional Positivo. 8. ed. São Paulo: Malheiros, 1992.

SKINNER, Frederic. Sobre o Behaviorismo. 4. ed. São Paulo: Cultrix, 2006.

VYGOTSKY, Lev. Pensamento e Linguagem. São Paulo: Martins Fontes, 1998. 